\title{
PENGEMBANGAN ANGKUTAN UMUM MASSAL BERBAGAI ALTERNATIF UNTUK MENGATASI KEMACETAN LALU LINTAS DI KOTA MADYA MALANG
}

\author{
Oleh : Ari Widayanti *)
}

\begin{abstract}
Abstrak
Jumlah armada dengan rute yang saling tumpah tindih akan mengakibatkan terjadinya kemacetan di beberapa lokasi pusat kegiatan masyarakat. Pada trayek ADL terjadi penumpukan armada dengan armada yang lain yang melewati rute yang sama seperti pada daerah Dinoyo. Daerah ini mempunyai akses langsung ke daerah pariwisata di kota Batu dan sekitarnya sehingga yang terjadi adalah mix traffic. Trayek yang melewati daerah Dinoyo terdiri dari trayek $A D L, A L$, LDG, LG, GL, AMG, JDM, CKL dan JPK. Dengan semakin meningkatnya kebutuhan akan jasa angkutan umum maka pelayanan angkutan umum dengan jenis mikrolet akan menimbulkan masalah karena tidak mempunyai kemampuan angkut yang tinggi. Trayek ADL dengan armada yang berjumlah 124 kendaraan perlu ditinjau kembali keberadaannya sehingga dapat dilakukan perencanaan angkutan massal untuk menuju kondisi angkutan umum yang efektif dan efisien.

Metode pengumpulan data dengan survei primer dan survei sekunder. Analisis data menggunakan rumus dan pedoman teknis dari Dirjenhubdat 1996.

Hasil yang diperoleh adalah nilai load factor sebesar 127,273 \%>100\%, dan nilai standar kenyamanan yang belum memenuhi kondisi yang ideal yaitu $0,251<0,3-0,55 \mathrm{~m}^{2}$. Hal ini mengindikasikan angkutan umum trayek ADL cukup dibutuhkan oleh masyarakat, tetapi kualitas/mutu pelayanan ditinjau dari fungsi kenyamanan belum memenuhi persyaratan, terutama pada saat peak hour. Kecepatan perjalanan berada dibawah standar yang seharusnya, hal ini disebabkan oleh adanya hambatan dalam perjalanan berupa lampu lalu lintas, kegiatan land use di sekitar jalan yang dilewati atau perilaku sopir yang memperlambat kendaraan untuk menaikkan atau menurunkan penumpang. Nilai Headway dibawah nilai ideal yaitu sebesar 1,179 menit. Hal ini menunjukkan jumlah armada yang beroperasi terlalu banyak sehingga perlu dilakukan pengurangan jumlah armada pada trayek ADL untuk dialokasikan pada trayek lain yang membutuhkan atau dilakukan perencanaan angkutan massal di Kotamadya Malang sehingga diperoleh angkutan umum yang efektif dan efisien.

Dari hasil perencanaan angkutan massal diperoleh model kapasitas 25 penumpang sejumlah 15 trip kendaraan dengan waktu tunggu penumpang sebesar 2,11 menit, model kapasitas 28 penumpang sejumlah 13 trip kendaraan dengan waktu tunggu penumpang sebesar 2,363 menit, model kapasitas 32 penumpang sejumlah 12 trip kendaraan dengan waktu tunggu penumpang sebesar 2,7 menit.
\end{abstract}

Kata Kunci: angkutan umum, load factor, headway, angkutan massal.

\section{PENDAHULUAN}

Wilayah perkotaan merupakan wilayah dengan jumlah penduduk yang padat dengan mobilitas masyarakat yang semakin tinggi dan bervariasi. Seseorang pada umumnya memerlukan pergerakan untuk memenuhi kebutuhan yang tidak dapat diperoleh di tempatnya. Hal ini akan terlaksana dengan baik apabila ada sarana dan prasarana transportasi yang mendukung, terutama angkutan umum.

Pada dasarnya dalam menggunakan angkutan umum, penumpang sebagai konsumen yang dilayani menghendaki pelayanan yang memadai ditinjau dari waktu tempuh perjalanan, waktu tunggu kendaraan, keamanan dan kenyamanan selama perjalanan. Dalam proses perencanaan perangkutan, berbagai prosedur telah dikembangkan untuk menurunkan atau menyebarkan pilihan moda yang ada yang didasarkan pada anggapan bahwa proporsi permintaan perjalanan yang dilayani oleh kendaraan umum dan kendaraan pribadi akan tergantung pada penampilan setiap moda dalam persaingan dengan moda yang lain. Persaingan tersebut diturunkan dari 3 faktor (Warpani, 1990) yaitu ciri perjalanan (misalnya jarak perjalanan, saat perjalanan dilakukan, tujuan perjalanan), ciri pelaku perjalanan (misalnya kepemilikan kendaraan pribadi, tingkat penghasilan, status sosial dalam kemasyarakatan),

\footnotetext{
*) Dosen Teknik Sipil

Universitas Negeri Surabaya
} 
ciri sistem perangkutan (misalnya lama perjalanan, biaya, daya hubung dan kenyamanan).

Kota Malang dengan jumlah penduduk pada tahun 2000 yang mencapai lebih dari 723.000 jiwa merupakan kota terbesar kedua di Jawa Timur setelah kota Surabaya yang berfungsi sebagai ibukota propinsi. Malang merupakan daerah pegunungan yang mempunyai ketinggian 444 meter di atas permukaan air laut. Dari kota Surabaya, Malang berjarak sekitar $80 \mathrm{~km}$ yang terhubung dengan jalan kolektor yang melewati Kabupaten Sidoarjo, Pasuruan dan Malang. Kota Malang mempunyai semboyan Tri Bina Cipta yaitu kota Malang sebagai kota industri, kota pariwisata dan kota pendidikan yang terbagi atas 5 daerah kecamatan yaitu: kecamatan Lowokwaru, Blimbing, Klojen, Sukun dan Kedungkandang.

Untuk melayani kebutuhan masyarakat kota Malang yang menggunakan angkutan umum dioperasikan Mobil Penumpang Umum (MPU) atau mikrolet dengan kapasitas 12 orang. Angkutan umum di kota Malang dikategorikan sebagai angkutan umum dengan trayek tetap dan teratur, tidak terjadwal dalam melayani penumpang yang berlangsung dari pagi hari jam 05.00 WIB sampai dengan jam 22.00 WIB. Diluar dari jadwal tersebut, mobilitas masyarakat dilayani oleh armada taksi yang jumlahnya cukup banyak di kota Malang.

Jumlah armada mikrolet yang ada saat ini secara keseluruhan adalah 2.176 kendaraan yang terbagi dalam 25 trayek/jalur. Salah satu dari trayek tersebut adalah jalur ADL (Arjosari-DinoyoLandungsari), dengan jumlah armada sejumlah 124 kendaraan yang melayani rute sepanjang 14,5 km dari Terminal Arjosari di wilayah Utara menuju Terminal Landungsari di wilayah Barat Laut. Arjosari merupakan terminal terbesar di kotamadya Malang yang termasuk dalam klasifikasi terminal $A$, sedangkan Landungsari merupakan terminal dengan klasifikasi tipe B. Kotamadya Malang terhubung dengan kota-kota orde dua di Propinsi Jawa Timur seperti Kabupaten Malang, Jombang, Pasuruan, Blitar, Lumajang, Kediri dan lain-lain. Rute yang ditempuh oleh trayek ADL adalah : Terminal Arjosari-Jl. Simpang Panji Suroso-Jl. Raden Intan-Jl. Letjen S. Parman-Jl. Letjen Sutoyo-Jl. Hamid Rusdi-Jl. Panglima Sudirman-Jl. Dr. Cipto-Jl. Cokroaminoto-Jl. Kertanegara-Jl. Tugu-Jl. Kahuripan-Jl. Semeru-Jl. Besar ljen-Jl. Bandung-Jl.
Veteran-Jl. Bogor-Jl. Mayjen Panjaitan-Jl. Mayjend Haryono-Jl. Raya TlogomasTerminal Landungsari dan sebaliknya.

Trayek ADL melewati daerah-daerah yang merupakan pusat-pusat kegiatan masyarakat yang berupa permukiman, pasar, pertokoan, perkantoran, perumahan, sekolah, Rumah Sakit dll. Daerah Dinoyo merupakan daerah yang dilewati trayek ADL dengan beragam pusat-pusat kegiatan yang berpotensi menimbulkan bangkitan perjalanan (Trip Production) dan tarikan perjalanan (Trip Attraction) dari masyarakat yang melakukan kegiatan sehari-hari. Dengan kondisi land use yang demikian ini seringkali menimbulkan tundaan perjalanan bahkan kemacetan lalu lintas. Beberapa studi telah dilakukan, namun solusi yang diberikan belum mampu mengatasi permasalahan yang terjadi. Studi tersebut antara lain pengaturan simpang dengan $U$ Turn maupun pengaturan simpang dengan lampu lalu lintas.

Dengan semakin meningkatnya kebutuhan akan jasa angkutan umum maka pelayanan angkutan umum dengan jenis mikrolet akan menimbulkan masalah karena tidak mempunyai kemampuan angkut yang tinggi. Syarat pijakan untuk teknologi angkutan massal diberlakukan apabila penduduk pada suatu daerah telah mencapai 1 juta jiwa. Dengan jumlah penduduk yang diperkirakan semakin meningkat pada tahun-tahun yang akan datang, maka kebutuhan akan angkutan umum massal di kota Malang merupakan salah satu solusi untuk mengatasi permasalahan yang terjadi. Dengan demikian perlu direncanakan angkutan massal yang sesuai untuk diberlakukan di Kotamadya Malang, khususnya pada trayek ADL.

\section{Permasalahan}

Jumlah armada dengan rute yang saling tumpah tindih akan mengakibatkan terjadinya kemacetan di beberapa lokasi pusat-pusat kegiatan masyarakat. Pada rute trayek ADL terjadi penumpukan armada dengan armada yang lain yang melewati rute yang sama seperti yang terjadi pada daerah Dinoyo. Daerah ini mempunyai akses langsung ke daerah pariwisata di kota Batu dan sekitarnya sehingga yang terjadi adalah mix traffic. Trayek yang melewati daerah Dinoyo terdiri dari trayek ADL, AL, LDG, LG, GL, AMG, JDM, CKL dan JPK.

Trayek ADL dengan armada yang berjumlah 124 kendaraan perlu ditinjau 
kembali keberadaannya sehingga dapat dilakukan perencanaan angkutan massal untuk dapat tercapai kondisi angkutan yang optimal. Bagaimana evaluasi terhadap kinerja angkutan umum serta model angkutan massal yang seperti apa yang dapat dijadikan sebagai pengembangan angkutan khususnya untuk trayek ADL di Kota Malang?

\section{Batasan}

Batasan dalam studi ini adalah:

1. Trayek yang ditinjau adalah trayek ADL.

2. Lokasi pengambilan data untuk survei primer di Jalan Mayjen Haryono sebagai salah satu daerah pusat kemacetan.

3. Evaluasi dan perencanaan hanya meninjau pada aspek teknis dan operasional kendaraan serta belum meninjau pada aspek prasarana jalan khususnya geometrik jalan dan aspek ekonomi.

\section{Tujuan}

Tujuan yang hendak dicapai adalah:

1. Melakukan evaluasi terhadap kinerja angkutan umum pada trayek ADL.

2. Merencanakan angkutan umum massal yang sesuai dengan kebutuhan masyarakat di Kota Malang.

\section{Manfaat} adalah:

Manfaat yang diperoleh dari studi ini

1. Dapat memberikan rekomendasi pada pihak terkait dalam mengatasi permasalahan angkutan umum dan lalu lintas yang terjadi di Kota Malang.

2. Sebagai wacana bagi pengaplikasian ilmu transportasi dalam mengatasi permasalahan yang terjadi pada masyarakat saat ini.

\section{KAJIAN PUSTAKA}

\section{Angkutan Penumpang Umum di Wilayah Perkotaan}

Secara umum untuk kondisi negara yang sedang berkembang, angkutan umum masih memegang peranan penting dalam menunjang pergerakan masyarakat. Dalam melakukan pemilihan moda, masyarakat dibagi atas 2 golongan yaitu Choice User dan Captive User. Choice user adalah kelompok masyarakat yang mempunyai pilihan dalam mobilitasnya yaitu antara menggunakan kendaraan pribadi atau kendaraan umum. Sedangkan Captive user adalah kelompok orang yang hanya mempunyai 1 pilihan yaitu menggunakan kendaraan umum dalam melakukan mobilitasnya karena keterbatasan fisik, finansial dan hukum yang dimilikinya (Tamin, 2000).

Jenis pelayanan angkutan umum menggunakan jenis Mobil Penumpang Umum (MPU) atau jenis bus. Pengangkutan orang dengan kendaraan umum dilayani dengan trayek tetap dan teratur serta tidak dalam trayek (Abubakar, 1996). Trayek tetap dan teratur adalah pelayanan angkutan yang dilakukan dalam jaringan trayek secara tetap dan teratur dengan jadwal tetap atau tidak berjadwal untuk pelayanan angkutan orang dengan kendaraan umum dalam trayek tetap dan tertentu yang dilakukan dalam jaringan trayek. Jaringan trayek adalah kumpulan dari trayek-trayek yang menjadi satu kesatuan pelayanan angkutan penumpang. Penentuan jaringan trayek didasarkan atas kebutuhan angkutan, kelas jalan yang sama dan atau lebih tinggi, tingkat pelayanan jalan, jenis pelayanan jalan, rencana umum tata ruang dan kelestarian lingkungan.

Trayek angkutan diklasifikasikan dalam 4 kategori yaitu (Abubakar, 1996):

a. Trayek Utama, adalah pelayanan angkutan yang melayani angkutan kawasan utama, antara kawasan utama dan kawasan pendukung dengan ciri-ciri sebagai berikut :

1. Melakukan perjalanan ulang-alik secara tetap,

2. Mempunyai jadwal tetap, sebagaimana tercantum dalam jam perjalanan pada kartu pengawasan kendaraan yang dioperasikan dan dilayani oleh jenis kendaraan bis umum,

3. Pelayanan angkutan secara terus menerus pada tempat-tempat untuk menaikkan dan menurunkan penumpang yang ditetapkan untuk angkutan kota,

4. Jumlah permintaan tinggi dan pelayanan dalam jarak pendek.

b. Trayek Cabang, adalah pelayanan angkutan yang melayani angkutan kawasan pendukung dan kawasan permukiman dengan ciri-ciri sebagai berikut :

1. Mempunyai jadwal tetap sebagaimana tercantum dalam jam perjalanan pada kartu pengawasan kendaraan yang dioperasikan,

2. Dilayani hanya oleh mobil bis umum,

3. Pelayanan angkutan secara terus menerus, berhenti pada tempattempat untuk menaikkan dan 
menurunkan penumpang yang telah ditetapkan untuk angkutan kota, pelayanan ekonomi dan atau non ekonomi,

4. Pelayanan jarak pendek.

c. Trayek Ranting, adalah pelayanan angkutan yang melayani angkutan dalam kawasan permukiman dengan ciri-ciri sebagai berikut :

1. Tidak mempunyai jadwal tetap,

2. Dilayani oleh mobil bus dan atau mobil penumpang umum,

3. Pelayanan angkutan secara terus menerus, berhenti pada tempattempat untuk menaikkan dan menurunkan penumpang yang telah ditetapkan untuk angkutan kota,

4. Pelayanan lintas dan jarak pendek.

d. Trayek Langsung, adalah pelayanan angkutan yang melayani angkutan antar kawasan utama dengan kawasan pendukung dan kawasan permukiman dengan ciri-ciri sebagai berikut :

1. Mempunyai jadwal tetap sebagaimana tercantum dalam jam perjalanan pada kartu pengawasan kendaraan yang dioperasikan,

2. Melayani angkutan antar kawasan, permintaan tinggi secara tetap serta bersifat massal dan langsung,

3. Dilayani oleh mobil bis umum dan non ekonomi,

4. Pelayanan angkutan secara terus menerus, berhenti pada tempattempat untuk menaikkan dan menurunkan penumpang yang telah ditetapkan untuk angkutan kota, pelayanan lintas dan jarak pendek.

Tabel 1. Kriteria Perencanaan Trayek

\begin{tabular}{lllc}
\hline Klasifikasi Trayek & $\begin{array}{c}\text { Jenis } \\
\text { Pelayanan }\end{array}$ & $\begin{array}{c}\text { Jenis } \\
\text { Angkutan }\end{array}$ & $\begin{array}{c}\text { Kapasitas Penumpang } \\
\text { perhari/kendaraan }\end{array}$ \\
\hline Utama & Cepat & Bis besar (DD) & $1500-1800$ \\
& Lambat & Bis besar ( SD ) & $1000-1200$ \\
Cabang & & Bis sedang & $500-600$ \\
& Cepat & Bis besar & $1000-1200$ \\
Ranting & Lambat & Bis sedang & $500-600$ \\
& & Bis kecil & $300-400$ \\
Langsung & Bis sedang & $500-600$ \\
& & Bis kecil & $300-400$ \\
& Cepat & MPU & $250-300$ \\
& & Bis besar & $1000-1200$ \\
& & Bis sedang & $500-600$ \\
& & Bis kecil & $300-400$ \\
\hline
\end{tabular}

Sumber : Menuju Lalu Lintas dan Angkutan Jalan yang Tertib (Abubakar, 1996).

Tabel 2. Penentuan Jenis Angkutan Berdasarkan Ukuran Kota

\begin{tabular}{|c|c|c|c|c|}
\hline $\begin{array}{l}\text { Ukuran Kota } \\
\text { Klasifikasi } \\
\text { Trayek }\end{array}$ & $\begin{array}{c}\text { Kota Raya } \\
>1.000 .000 \\
\text { penduduk }\end{array}$ & $\begin{array}{c}\text { Kota Besar } \\
500.000-1.000 .000 \\
\text { penduduk }\end{array}$ & $\begin{array}{c}\text { Kota Sedang } \\
100.000-500.000 \\
\text { penduduk }\end{array}$ & $\begin{array}{l}\text { Kota Kecil } \\
<100.000 \\
\text { penduduk }\end{array}$ \\
\hline Utama & $\begin{array}{l}\text { KA } \\
\text { Bis besar } \\
\text { ( SD/DD ) }\end{array}$ & Bis besar & Bis besar / sedang & Bis sedang \\
\hline Cabang & $\begin{array}{l}\text { Bis } \\
\text { besar/sedang }\end{array}$ & Bis sedang & Bis sedang / kecil & Bis kecil \\
\hline Ranting & $\begin{array}{l}\text { Bis } \\
\text { sedang/kecil }\end{array}$ & Bis kecil & MPU & MPU \\
\hline Langsung & Bis besar & Bis besar & Bis sedang & Bis sedang \\
\hline
\end{tabular}

Keterangan : $\mathrm{DD}=$ lantai ganda, $\quad \mathrm{SD}=$ lantai tunggal

Sumber : Menuju Lalu Lintas dan Angkutan Jalan yang Tertib (Abubakar, 1996). 


\section{Kecepatan Kendaraan}

Kecepatan adalah jarak yang ditempuh dalam satuan waktu atau nilai perubahan jarak terhadap waktu, yang dinyatakan dalam dd/dt. Kecepatan kendaraan dipengaruhi oleh faktor manusia, kendaraan dan prasarana, arus lalu lintas, kondisi cuaca dan lingkungan.

Kecepatan merupakan parameter yang penting khususnya dalam desain jalan, sebagai informasi mengenai kondisi perjalanan, tingkat pelayanan dan kualitas arus lalu lintas yang berupa kemacetan Ialu lintas. Kemacetan lalu lintas umumnya tidak dikehendaki, karena akan menimbulkan:

1. Peningkatan waktu dan biaya perjalanan,

2. Peningkatan biaya operasi kendaraan (Vehicle Operating Cost),

3. Peningkatan jumlah angka kecelakaan,

4. Penurunan kenyamanan pengemudi,

5. Pengaruh pada tingkah laku pengemudi.

Klasifikasi utama yang sering digunakan yaitu:

a. Kecepatan Sesaat / Titik (Spot Speed) Kecepatan titik adalah kecepatan kendaraan sesaat pada waktu kendaraan tersebut melintasi suatu titik tetap tertentu di jalan.

b. Kecepatan Perjalanan (Journey Speed) Kecepatan perjalanan adalah kecepatan rata-rata kendaraan efektif antara dua titik tertentu di jalan, yang dapat ditentukan dari jarak perjalanan dibagi dengan total waktu perjalanan, yang dihitung dengan persamaan :

$\mathrm{V}=\mathrm{S} / \mathrm{t}$

Dengan :

$\mathrm{V}$ = kecepatan perjalanan $(\mathrm{km} / \mathrm{jam})$

$\mathrm{S}=$ jarak perjalanan $(\mathrm{km})$

$\mathrm{t}=$ total waktu perjalanan (jam)

c. Kecepatan Bergerak (Running Speed)

Kecepatan bergerak adalah kecepatan rata-rata kendaraan untuk melintasi jarak tertentu dalam kondisi kendaraan tetap berjalan, yaitu kondisi setelah dikurangi oleh waktu hambatan yang terjadi, misalnya hambatan pada persimpangan, naik turun penumpang, menunggu penum-pang dan kemacetan lalu lintas.

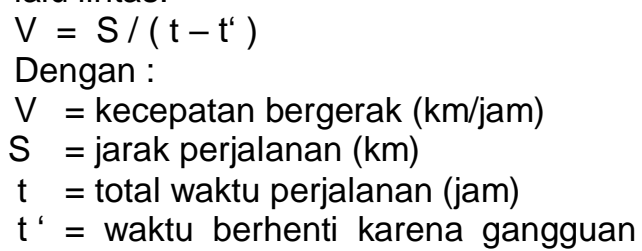

lalu lintas (jam).

\section{Waktu Tunggu Penumpang}

Waktu tunggu adalah waktu yang diperlukan oleh calon penumpang untuk menunggu kendaraan angkutan umum, yang mana waktu tunggu rata-rata dapat diartikan setengah dari nilai frekuensinya. Frekuensi yang paling sedikit sama dengan frekuensi minimum yang dianggap dapat diterima untuk pelayanan angkutan.

$\mathrm{f}<\mathrm{F}=1 / \mathrm{H}$

Dengan:

$\mathrm{f}=$ frekuensi keberangkatan angkutan untuk satu arah (kendaraan/jam)

$\mathrm{F}=$ frekuensi minimum yang dapat diterima (kendaraan/jam)

$\mathrm{H}=$ headway maksimum yang dapat diterima,

Headway adalah jarak atau waktu antar kendaraan.

Volume penumpang dapat melampaui volume yang dapat ditampung oleh kendaraan yang beroperasi pada frekuensi yang minimum. Untuk itu frekuensi harus lebih besar atau sama dengan yang dibutuhkan untuk dapat menampung arus penumpang pada setiap periode tertentu. Penentuan frekuensi untuk pengoperasian jumlah perjalanan yang minimum agar memenuhi kedua kriteria di atas harus mengikuti (Morlok, 2000) :

$\mathrm{f}=$ maksimum $(\mathrm{F}, \mathrm{P} / \mathrm{Q})$

Dengan:

$\mathrm{P}=$ arus penumpang melalui titik beban puncak pada rute penumpang/jam.

$\mathrm{Q}=$ kapasitas kendaraan (penumpang/kendaraan).

Apabila dianggap kedatangan penumpang yang seragam atau acak pada perhentian di tempat asal dan headway waktu konstan diantara kendaraan, maka waktu menunggu rata-rata akan menjadi setengah headway (Morlok, 2000).

$\mathrm{w}=\mathrm{h} 1 / 2=60 / 2 \mathrm{f}$

Dengan:

$\mathrm{w}=$ waktu tunggu (menit)

h1 = headway kendaraan pada saat tidak sibuk (menit/kendaraan)

\section{Dasar Penentuan Jumlah Armada}

Jumlah armada angkutan yang tepat sesuai dengan kebutuhan sulit ditentukan, yang dapat dilakukan adalah mendekati besarnya kebutuhan. Kebutuhan jumlah armada angkutan dipengaruhi oleh jumlah penumpang pada jam puncak, kapasitas kendaraan, standar beban tiap kendaraan dan waktu perjalanan satu putaran. 
a. Faktor Muat (Load Factor)

Faktor Muat (load factor) merupakan perbandingan antara kapasitas terjual (operasional) dengan kapasitas tersedia untuk satu perjalanan, yang dinyatakan dalam persen.

Kapasitas kendaraan adalah daya muat penumpang pada angkutan umum baik yang duduk maupun berdiri, yang mana daya muat untuk setiap jenis angkutan berbeda-beda.

$\mathrm{Co}=\left(3600{ }^{*} \mathrm{Cv}{ }^{*} \mathrm{n}\right) / \mathrm{H}$

Dengan:

Co $=$ kap. operasional dalam 1 jam .

$\mathrm{Cv}=$ kapasitas kendaraan (penump.)

$\mathrm{n}=$ jumlah kendaraan per transit (unit).

$\mathrm{H}=$ headway (detik).

b. Waktu Sirkulasi

Waktu sirkulasi adalah waktu yang diperlukan satu unit angkutan untuk menjalani satu trayek dimulai dari terminal awal menuju terminal tujuan, kembali ke terminal awal.

$\mathrm{CT}_{\mathrm{ADLA}}=\left(\mathrm{TT}_{\mathrm{ADL}}+\mathrm{TT}_{\mathrm{LDA}}\right)+\left(\mathrm{LT}_{\mathrm{A}}+\mathrm{LT}_{\mathrm{L}}\right)$

Dengan:

$\mathrm{CT}_{\mathrm{ADLA}}=$ waktu sirkulasi (Circular Timer) dari terminal A ke $\mathrm{L}$ dan kembali ke A.

$\mathrm{TT}_{\mathrm{ADL}}=$ waktu perjalanan rata-rata dari A ke L.
$\mathrm{TT}_{\text {LDA }}=$ waktu perjalanan rata-rata dari $L$ ke $A$.

$\mathrm{LT}_{\mathrm{A}} \quad=$ waktu henti kendaraan di terminal $A$.

$\mathrm{LT}_{\mathrm{L}} \quad=$ waktu henti kendaraan di terminal $L$.

$H=(60 * C * L f) / P$

Dengan:

$\mathrm{H}=$ waktu antara / headway (menit).

$\mathrm{C}=$ kapasitas kendaraan (penumpang)

$\mathrm{Lf}=$ faktor muat (\%).

$\mathrm{P}=$ jumlah penumpang.

c. Jumlah armada per waktu sirkulasi ditentukan dengan :

$\mathrm{K}=\mathrm{CT} /(\mathrm{h}$ * $\mathrm{fA})$

Frekuensi kendaraan (waktu pengamatan) per-jam :

$F_{K J}=(W / H)$

Dengan:

$\mathrm{K} \quad$ = jumlah kendaraan per waktu sirkulasi (unit)

CT = waktu sirkulasi (menit)

$\mathrm{H} \quad=$ waktu antara (menit)

$\mathrm{fA}=$ faktor ketersediaan kendaraan $(100 \%)$

$\mathrm{W}=$ periode waktu operasi per jam (60 menit) dalam menit

$\mathrm{F}_{\mathrm{KJ}}=$ frekuensi kendaraan (trip kendaraan)

Tabel 3. Kapasitas Kendaraan

\begin{tabular}{lcccc}
\hline \multicolumn{1}{c}{ Jenis Angkutan } & \multicolumn{2}{c}{ Kapasitas Kendaraan } & Kapasitas Penumpang \\
& Duduk & Berdiri & Total & per-hari / kend. \\
\hline Mobil Penumpang Umum & 11 & - & 11 & $250-300$ \\
Bis Kecil & 14 & - & 14 & $300-400$ \\
Bis Sedang & 20 & 10 & 30 & $500-600$ \\
Bis Besar Lantai Tunggal & 49 & 30 & 79 & $1000-1200$ \\
Bis Besar Lantai Ganda & 85 & 35 & 120 & $1500-1800$ \\
\hline
\end{tabular}

Sumber: Direktorat Jenderal Perhubungan Darat, 1996.

d. Kecepatan Tempuh

Sebagai acuan, berikut ini adalah Indeks Tingkat Pelayanan berdasarkan kecepatan pelayanan rata-rata dan berdasarkan arus bebas serta tingkat kejenuhan lalu lintas.

Tabel 4. Indeks Tingkat Pelayanan Berdasarkan Kecepatan Pelayanan Rata-rata

\begin{tabular}{|c|c|c|c|}
\hline $\begin{array}{c}\text { Kelas Jalan Arteri } \\
\text { Kecepatan ( km / jam ) } \\
\text { ITP }\end{array}$ & $\begin{array}{c}I \\
72-56\end{array}$ & $\begin{array}{l}\text { II } \\
56-48 \\
\text { rialanan }\end{array}$ & $\begin{array}{c}\text { III } \\
56-40\end{array}$ \\
\hline$A$ & $>56$ & $>48$ & $>40$ \\
\hline B & $>45$ & $>38$ & $>31$ \\
\hline C & $>35$ & $>29$ & $>21$ \\
\hline D & $>28$ & $>23$ & $>15$ \\
\hline$E$ & $>21$ & $>16$ & $>11$ \\
\hline$F$ & $<21$ & $<16$ & $<11$ \\
\hline
\end{tabular}

Sumber : Tamin, Ofyar Z., 2000. 
Tabel 5. Indeks Tingkat Pelayanan Berdasarkan Arus Bebas dan Tingkat Kejenuhan Lalu Lintas

\begin{tabular}{ccc}
\hline Tingkat Pelayanan & \% dari Kecepatan Bebas & Tingkat Kejenuhan Lalu Lintas \\
\hline A & $>90$ & $>0,35$ \\
B & $>70$ & $>0,54$ \\
C & $>50$ & $>0,77$ \\
D & $>40$ & $>0,93$ \\
E & $>33$ & $>1,0$ \\
F & $<33$ & $<1,0$
\end{tabular}

Sumber : Tamin, Ofyar Z., 2000.

e. Waktu Tempuh Perjalanan

Waktu tempuh perjalanan dibagi 2 yaitu :

1. Travel time adalah jumlah waktu yang dilewati termasuk stop dan delay yang diperlukan oleh kendaraan untuk berjalan dari satu titik ke titik yang lain melalui rute tertentu dan pada kendaraan lalu lintas yang ada.

2. Running time adalah bagian dari travel time dimana kendaraan sesungguhnya berjalan.

\section{f. Tundaan (Delay)}

Tundaan (delay) merupakan waktu yang hilang pada saat lalu lintas tertahan atau terhambat yang diakibatkan oleh beberapa elemen lalu lintas dimana pengemudi tidak mempunyai kontrol atau tidak dapat mengatasi tekanan/hambatan lalu lintas yang terjadi.

Tundaan (delay) dibagi atas:

1. Operational delay adalah delay yang disebabkab oleh gangguan atau hambatan diantara komponen lalu lintas.

2. Fixed delay adalah delay yang disebabkan oleh pengatur lalu lintas terutama pada persimpangan, misalnya lampu lalu lintas, tanda stop, tanda memberi jalan, persilangan kereta api dan lain-lain.

3. Stopped time delay adalah periode waktu dimana kendaraan berhenti tetap pada suatu tempat atau stationer karena sesuatu hal yang mempengaruhi perjalanan.

4. Travel time delay adalah delay yang disebabkan oleh perbedaan waktu yang dibutuhkan untuk menjalani suatu bagian jalan dan waktu yang berhubungan dengan kecepatan ratarata lalu lintas pada titik yang arus lalu lintasnya tidak penuh sesak pada bagian jalan tersebut. g. Jarak Tempuh Perjalanan

Jarak tempuh perjalanan adalah panjang dari rute atau jalur yang harus dilewati oleh kendaraan yang sifatnya tetap dengan mengukur jarak dari tempat asal ke tujuan yang dilalui oleh kendaraan yang bersangkutan.

h. Kapasitas Kendaraan

Kapasitas kendaraan adalah nilai yang menyatakan jumlah space (ruang bebas) penumpang yang meliputi jumlah tempat duduk dan jumlah tempat berdiri pada suatu kendaraan. Untuk angkutan kota atau mobil penumpang umum, kapasitas hanya meliputi jumlah tempat duduk maksimum pada kendaraan.

Total Capacity adalah sejumlah tempat berdiri dan tempat duduk yang dinyatakan dalam $\mathrm{m}^{2}$.

Seating Capacity adalah sejumlah tempat duduk yang tersedia.

Faktor-faktor yang mempengaruhi penentuan kapasitas kendaraan adalah:

1. Dimensi kendaraan, meliputi panjang, lebar dan jumlah lantai yang mengindikasikan luas lantai kotor.

2. Area terpakai, yaitu luas bersih lantai kendaraan yang dapat dipakai oleh penumpang. Luas lantai bersih adalah luas kotor yang telah dikurangi tebal dinding kendaraan, pengurangan badan pada ujung-ujung kendaraan untuk clearance di tikungan, area yang tidak dapat dipakai oleh penumpang misalnya: cabin (tempat pengemudi, mesin).

Untuk menentukan kapasitas kendaraan angkutan umum yang hanya menyediakan tempat duduk bagi penumpang tanpa tempat untuk berdiri, maka besarnya kapasitas kendaraan sama dengan jumlah tempat duduk. Untuk lebih jelasnya dapat ditulis dalam bentuk persamaan berikut ini: 
$\mathrm{Cv}=\mathrm{m}$

Dengan:

$\mathrm{Cv}=$ kapasitas kendaraan (space/ kendaraan)

$\mathrm{m}$ = jumlah tempat duduk penumpang (space)

i. Kapasitas Jalur Kendaraan (c) Kapasitas jalur kendaraan adalah jumlah kendaraan yang melewati suatu titik selama waktu terukur untuk setiap jalurnya, atau biasa disebut frekuensi kendaraan yang lewat dalam satu satuan waktu.

$c=f \times n$

Dengan:

$\mathrm{C}=$ kapasitas jalur kendaraan (kendaraan/jam)

$f=$ frekuensi lewat kendaraan (Transit Unit/jam)

$\mathrm{n}=$ jumlah jenis kendaraan tiap transyt unit (kendaraan/TU).

j. Kapasitas Jalur (C)

Kapasitas jalur adalah hasil perkalian kapasitas kendaraan (Cv) dengan kapasitas jalur kendaraan (c) :

$\mathrm{C}=\mathrm{c} \times \mathrm{Cv}$ atau $\mathrm{C}=\mathrm{f} \times \mathrm{n} \times \mathrm{Cv}$

Dengan :

C = kapasitas jalur (space/jam)

C = kapasitas jalur kendaraan (kendaraan/jam )

Cv = kapasitas kendaraan (space/kendaraan )

$\mathrm{f}=$ frekuensi lewat kendaraan (TU/jam)

$\mathrm{n} \quad=$ jumlah jenis kendaraan tiap unit (kendaraan/TU).

\section{k. Headway}

Headway adalah interval waktu antara dua transyt unit yang berurutan.

Pengertian ini dapat dibagi 2 yaitu:

Way headway adalah headway yang diukur pada suatu titik dalam lintasan angkutan antara dua stasiun terminal.

Station headway adalah headway yang diukur pada atau di stasiun.

Persamaan umum headway adalah:

$\mathrm{h}=(3600 / \mathrm{f})$

Dengan:

$\mathrm{h}=$ headway (detik/TU)

$\mathrm{f} \quad=$ frekuensi pelayanan (TU/jam)

Pada umumnya untuk mempermudah perhitungan, besarnya headway disesuaikan dengan kondisi keadaan masyarakat setempat. Dalam hal ini headway maksimum diasumsikan sebesar 10 menit atau 600 detik.

Jadi besarnya frekuensi minimum adalah: $\mathrm{f} \quad=(3600 / 600 \mathrm{dtk} / \mathrm{jam})=6 \mathrm{TU} / \mathrm{jam}$.

Load factor adalah nilai prosentase yang diperoleh dari hasil perbandingan antara jumlah penumpang dalam suatu kendaraan dengan kapasitas tempat duduk (seat capacity).

Load Factor $=$ (jumlah penumpang/jumlah tempat duduk) x $100 \%$

\section{METODE \\ Rancangan Data Penelitian}

Data yang diperlukan meliputi data primer yang diperoleh dari lapangan, serta data sekunder yang didapatkan dari studi terdahulu dan instansi terkait.

Survei primer dilakukan pada Jalan Mayjen Haryono sebagai salah satu daerah pusat kemacetan di kota Malang. Lokasi ini dipilih karena setiap hari selalu timbul kemacetan terutama pada saat peak hour baik pagi maupun sore hari. Lokasi ini merupakan daerah dengan kondisi land use yang kompleks, terdiri dari permukiman, pendidikan, pasar, perumahan, perkantoran, selain itu juga merupakan akses ke daerah pariwisata Batu yang berpotensi menimbulkan kemacetan lalu lintas terutama pada saat akhir pekan.

Data primer terdiri dari:

1. Rute angkutan lyn ADL yang ditinjau.

2. Jumlah penumpang kendaraan tiap trip per-satuan waktu dengan Off Board Survey.

3. Frekuensi kendaraan per-satuan waktu, Headway dan waktu tunggu penumpang.

4. Jumlah penumpang per-kendaraan dengan On Board Survey dan Off Board Survey, waktu tempuh, waktu hambatan dan waktu perjalanan kendaraan.

Data sekunder terdiri dari:

2. Daftar jalur trayek dan jumlah kendaraan angkutan umum di Kotamadya Malang.

3. Data jumlah penduduk.

\section{Pengumpulan Data}

Pengumpulan data dengan survei primer dibagi dalam tahapan sebagai berikut:

2. Identifikasi rute yang dilewati trayek ADL.

3. Observasi langsung dengan On Board Survey (mengikuti pergerakan kendaraan dengan naik langsung pada lyn ADL). Data yang diperoleh berupa waktu perjalanan, waktu hambatan serta 
data naik turun penumpang pada rute yang ditinjau.

4. Observasi langsung dengan Off Board Survey yaitu mencatat frekuensi kendaraan dan jumlah penumpang yang naik kendaraan pada titik-titik pengamatan.

5. Observasi langsung waktu henti kendaraan di Terminal Arjosari dan Terminal Landungsari. Pengumpulan data dilakukan dengan mencatat jam masuk dan jam keluar lyn ADL dari terminal.

\section{Analisis Data}

Data yang sudah diperoleh dalam survei primer dan sekunder, kemudian dianalisis menggunakan rumus berdasarkan pedoman teknis dan referensi lain yang terkait (Direktorat Jenderal Perhubungan Darat, 1996)

\section{HASIL DAN PEMBAHASAN Analisis Teori Pembatas}

e. Kapasitas kendaraan (Cv) $=11$ space/kendaraan........kondisi ideal.

f. Kapasitas jalur kendaraan (c)

Nilai headway ideal $=5-10$ menit, sedangkan headway pada kondisi puncak $=2-5$ menit (Direktorat Jenderal Perhubungan Darat, 1996 ).

$\mathrm{h}_{\text {min }}$ (headway) $=2$ menit $=120$ detik

Frekuensi $(\mathrm{f}$ maks $)=(3600$ detik $) /(120$ $\operatorname{detik} / \mathrm{TU})=30 \mathrm{TU}$

$\mathrm{h}_{\text {maks }}($ headway $)=10$ menit

$$
=600 \text { detik }
$$

Frekuensi $(\mathrm{fmin}) \quad=(3600$ detik $) /(600$

$\operatorname{detik} / T U)=6 \mathrm{TU}$

$\mathrm{c}=\mathrm{f} \times \mathrm{n}$

$\mathrm{n}=1$ kendaraan $/ \mathrm{TU}$

$\mathrm{c}_{\text {maks }}=30 \mathrm{TUx} 1 \mathrm{kend} . / \mathrm{TU}$

$$
=30 \text { kend. } / \mathrm{jam}
$$

$\mathrm{C}_{\min }=6 \mathrm{TU} \times 1 \mathrm{kendaraan} / \mathrm{TU}$

$$
=6 \text { kendaraan/jam }
$$

g. Kapasitas jalur (C)

$\mathrm{C}=\mathrm{C} \times \mathrm{Cv}$

$\mathrm{C}_{\text {maks }}=30$ kendaraan/jam $\times 11$ space/kendaraan = 330 space/jam

$\mathrm{C}_{\min }=6$ kendaraan/jam $\times 11$

space/kendaraan $=66$ space/jam

h. Load factor

Nilai load factor yang ideal seharusnya dibawah $100 \%$

i. Standar kenyamanan

Luas kendaraan per-unit kapasitas

$$
=3,51 \mathrm{~m}^{2}
$$

Batasan ruang untuk kenyamanan

$$
=0,3-0,55 \mathrm{~m}^{2}
$$

Kapasitas kendaraan (mikrolet) yang

ideal $=11$ space

Standar kenyamanan angkutan kota

$=(3,51 / 11)=0,32 \mathrm{~m}^{2}$

\section{Analisis Data Hasil Survei}

j. Jumlah armada angkutan kota adalah 124 kendaraan.

k. Jarak tempuh antara Terminal Arjosari dan Terminal Landungsari $=$ $14,5 \mathrm{~km}$

I. Waktu perjalanan rata-rata $=40$ menit.

m. Kecepatan $=14,5 /(40 / 60)$

$$
=21,75 \mathrm{~km} / \mathrm{jam} \text {. }
$$

n. Kapasitas jalur kendaraan (c)

$\mathrm{h}_{\text {rata-rata }}$ (headway) $=1,179$ menit $=70,746$ detik

Frekuensi $\left(f_{\text {rata-rata }}\right)=(3600$ detik $) /$

$(70.746 \mathrm{detik} / \mathrm{TU})=51 \mathrm{TU}$

$\mathrm{c}=\mathrm{f} \times \mathrm{n}$

$\mathrm{n}=1$ kendaraan/TU

$\mathrm{c}_{\text {rata-rata }}=51 \mathrm{TU} \times 1 \mathrm{kendaraan} / \mathrm{TU}$ $=51 \mathrm{kendaraan} / \mathrm{jam}$

o. Kapasitas jalur (C)

$\mathrm{C}=\mathrm{c} \times \mathrm{Cv}$

$\mathrm{C}_{\text {maks }}=51$ kendaraan/jam $\times 11$ space $/$ kendaraan $=561$ space/jam

p. Load factor

Nilai load factor $=(14 \mathrm{org} / 11$ space $) \mathrm{x}$ $100 \%=127,273 \%>100 \%$.

q. Standar kenyamanan

Luas kendaraan perunit kapasitas $=3,51 \mathrm{~m}^{2}$

Batasan ruang untuk kenyamanan $=0,3-0,55 \mathrm{~m}^{2}$

Kapasitas kendaraan (mikrolet) yang termuat $=14$ space

Standar kenyamanan angkutan kota $=(3,51 / 14)=0,251 \mathrm{~m}^{2}<0,3-0,55 \mathrm{~m}^{2}$

\section{Analisis Kinerja Angkutan Umum}

Berdasarkan hasil On Board Survey, diperoleh bahwa angkutan umum trayek ADL melewati kawasan pusat kegiatan masyarakat seperti: perkantoran, pendidikan, permukiman, perumahan, pertokoan, sekolah, Rumah Sakit dan lain-lain. Hal ini memungkinkan untuk dapat memenuhi kebutuhan masyarakat dalam mobilitas sehari-hari. Ditinjau dari aksesibilitas (kemudahan pencapaian), rute trayek ADL mudah dijangkau oleh masyarakat.

Dari hasil perhitungan, menunjukkan kapasitas lebih besar dari yang seharusnya. Hal ini dapat dilihat dari nilai load factor $(127,273 \%>100 \%)$ dan nilai standar kenyamanan yang belum memenuhi kondisi yang ideal $\left(0,251<0,3-0,55 \mathrm{~m}^{2}\right)$. Hal ini 
mengindikasikan ang-kutan umum trayek ADL tersebut cukup dibutuhkan oleh masyarakat, akan tetapi kualitas atau mutu pelayanan terhadap fungsi kenyamanan belum memenuhi persyaratan, terutama pada saat peak hour.

Dari analisis terhadap kecepatan, diperoleh nilai dibawah standar yang seharusnya, jika dibandingkan dengan nilai yang terdapat pada Tabel 4 dan Tabel 5 . Hal ini kemungkinan disebabkan oleh adanya hambatan dalam perjalanan baik berupa hambatan oleh elemen lalu lintas misalnya lampu lalu lintas, kegiatan land use di sekitar jalan yang dilewati ataupun perilaku sopir yang sengaja memperlambat kendaraannya untuk menaikkan atau menurunkan penumpang.

Headway yang diperoleh berada di bawah nilai ideal yaitu sebesar 1,179 menit (nilai ideal sebesar 5-10 menit, sedangkan headway pada saat peak hour sebesar 2-5 menit). Dengan headway yang terlalu cepat menunjukkan bahwa jumlah armada yang beroperasi terlalu banyak sehingga perlu ditinjau kembali keberadaannya. Solusinya adalah melakukan pengurangan jumlah armada pada trayek ADL untuk dialokasikan pada trayek lain yang membutuhkan atau dilakukan perencanaan terhadap angkutan umum di Kotamadya Malang sehingga diperoleh angkutan yang lebih sesuai dengan perkembangan saat ini dan pada masa yang akan datang.

\section{Perencanaan Angkutan Umum}

Dalam perencanaan angkutan umum yang sesuai diberlakukan di Kotamadya Malang, diperlukan data berupa jumlah penumpang, waktu perjalanan, waktu henti kendaraan di terminal, panjang jalan, prediksi kecepatan kendaraan. Data diperoleh melalui survei di lapangan dan survei sekunder dari hasil studi sebelumnya.

1. Penentuan Jenis Kendaraan

Jenis kendaraan yang digunakan sebagai model adalah kendaraan angkutan umum yang dipergunakan di beberapa kota lain seperti Yogyakarta, Semarang, Surabaya dan lain-lain.

Kapasitas kendaraan adalah kapasitas total yang merupakan penjumlahan kapasitas tempat duduk dan kapasitas berdiri dengan kondisi ideal, artinya penumpang tidak berdesak-desakan sehingga walaupun penumpang berdiri namun masih ada kelonggaran untuk bergerak.

Tabel 6. Jenis dan Kapasitas Kendaraan Model

\begin{tabular}{|c|c|c|c|c|c|c|}
\hline \multirow[t]{2}{*}{ Model } & \multirow{2}{*}{$\begin{array}{c}\text { Jenis } \\
\text { Kendaraan }\end{array}$} & \multicolumn{3}{|c|}{ Kapasitas } & \multirow[t]{2}{*}{ Merk } & \multirow[t]{2}{*}{ Tahun } \\
\hline & & Duduk & Berdiri & Total & & \\
\hline 1 & MPU & $12^{*}$ & - & 12 & Suzuki ST 100 SP Carry & 2000 \\
\hline 2 & MPU & $16^{*}$ & - & 16 & Mitsubishi Colt T 120 SS & 2000 \\
\hline 3 & Micro Bus & 17 & 8 & 25 & $\begin{array}{l}\text { Mitsubishi Colt FE } 101 \text { BRY/ } \\
\text { Tunggal }\end{array}$ & 1999 \\
\hline 4 & Micro Bus & $20^{*}$ & 8 & 28 & Mitsubishi Colt T 100 PS / Tunggal & 1999 \\
\hline 5 & Micro Bus & 24 & 8 & 32 & Mitsubishi Colt FE 119 PS / Ganda & 2000 \\
\hline 6 & Micro Bus & 30 & 8 & 38 & Mitsubishi Colt FE 349 PS / Ganda & 2000 \\
\hline 7 & Micro Bus & 38 & 16 & 54 & Mercedes Benz M 80800/38 & 2000 \\
\hline 8 & Bus & $49^{*}$ & 34 & 85 & Mercedes Benz CH 1518 / 50 & 2000 \\
\hline 9 & Bus & 60 & 30 & 90 & Mercedes Benz CH 1521 / 60 & 2000 \\
\hline
\end{tabular}

Sumber: Burhamtoro, 2001.

\section{Jumlah Armada}

Jumlah armada yang tepat sesuai dengan kebutuhan sulit dipastikan, yang dapat diperkirakan adalah mendekati besarnya kebutuhan yang terjadi. Variabel yang berpengaruh dalam hal ini adalah jumlah penumpang, kapasitas kendaraan, waktu perjalanan untuk satu kali putaran.

Perhitungan menggunakan 3 model kendaraan, yang terdapat pada Tabel 6, yaitu:

a. Model dengan kapasitas penumpang 25 orang.
Jumlah penumpang maksimum = 320 orang/jam

Kapasitas bus $\quad=25$ penumpang

Waktu perjalanan $\mathrm{TT}_{\mathrm{ADL}}=40$ menit

Waktu Perjalanan $\mathrm{TT}_{\mathrm{LDA}}=40$ menit

Waktu henti di Terminal Arjosari $=\mathrm{LT}_{\mathrm{A}}$

$=58 / 8=7,25$ menit

Waktu henti di Terminal Landungsari $=$

$\mathrm{LT}_{\mathrm{L}}=53 / 6=8,83$ menit

Faktor ketersediaan angkutan, diasumsikan $\mathrm{fA}=100 \%$. 
Waktu sirkulasi dari Terminal Arjosari ke Terminal Landungsari dan kembali ke Terminal Arjosari lagi:

$$
\begin{aligned}
\mathrm{CT}_{\mathrm{ADLA}} & =\left(\mathrm{TT}_{\mathrm{ADL}}+\mathrm{TT}_{\mathrm{LDA}}\right)+\left(\mathrm{LT}_{\mathrm{A}}+\mathrm{LT}_{\mathrm{L}}\right) \\
& =(40+40)+(7,25+8,83) \\
& =96,08 \text { menit. }
\end{aligned}
$$

Waktu antara:

$$
\begin{aligned}
H & =(60 \times C \times L f) / P=(60 \times 25 \times 0,9) / 320 \\
& =4,219 \text { menit }
\end{aligned}
$$

Jumlah armada per waktu siklus :

$\mathrm{K}=\mathrm{CT}_{\mathrm{ADLA}} /(\mathrm{HxfA})$

$=96,08 /(4,219 \times 1)$

$=22,773$ menit, ditentukan 23 menit.

Jumlah kendaraan yang lewat/jam

sibuk (60 menit) :

$\mathrm{F}_{\mathrm{KJ}}=(\mathrm{W} / \mathrm{H})=60 / 4,219$

$=14,221$, ditetapkan 15 trip kend.

b. Model dengan kapasitas penumpang 28 orang

Jumlah penumpang maksimum = 320 orang/jam

Kapasitas bus $=28$ penumpang

Waktu perjalanan $\mathrm{TT}_{\mathrm{ADL}}=40$ menit

Waktu Perjalanan $\mathrm{TT}_{\mathrm{LDA}}=40$ menit

Waktu henti di Terminal Arjosari $=\mathrm{LT}_{\mathrm{A}}$ $=58 / 8=7,25$ menit

Waktu henti di Terminal Landungsari $=$ $\mathrm{LT}_{\mathrm{L}}=53 / 6=8,83$ menit

Faktor ketersediaan angkutan,diasumsikan $\mathrm{fA}=100 \%$.

Waktu sirkulasi dari Terminal Arjosari ke

Terminal Landungsari dan kembali ke

Terminal Arjosari lagi:

$$
\begin{aligned}
\mathrm{CT}_{\mathrm{ADLA}} & =\left(\mathrm{TT}_{\mathrm{ADL}}+\mathrm{TT}_{\mathrm{LDA}}\right)+\left(\mathrm{LT}_{\mathrm{A}}+\mathrm{LT}_{\mathrm{L}}\right) \\
& =(40+40)+(7,25+8,83) \\
& =96,08 \text { menit }
\end{aligned}
$$

Waktu antara :

$$
\begin{aligned}
\mathrm{H} & =(60 \times \mathrm{C} \times \mathrm{Lf}) / \mathrm{P} \\
& =(60 \times 28 \times 0,9) / 320 \\
& =4,725 \text { menit }
\end{aligned}
$$

Jumlah armada per waktu siklus :

$\mathrm{K}=\mathrm{CT}_{\mathrm{ADLA}} /(\mathrm{H} \times \mathrm{fA})$

$=96,08 /(4,725 \times 1)$

$=20,334$ menit, ditetapkan 21 menit.

Jumlah kendaraan yang lewat/jam

sibuk (60 menit) :

$F_{K J}=(W / H)=60 / 4,725$

$=12,698$, ditetapkan 13 trip kend.

c. Model dengan kapasitas penumpang 32 orang

Jumlah penumpang maksimum = 320 orang / jam

Kapasitas bus $=32$ penumpang

Waktu perjalanan $\mathrm{TT}_{\mathrm{ADL}}=40$ menit

Waktu Perjalanan TT LDA $=40$ menit

Waktu henti di Terminal Arjosari $=\mathrm{LT}_{\mathrm{A}}$ $=58 / 8=7,25$ menit

Waktu henti di Terminal Landungsari =
$\mathrm{LT}_{\mathrm{L}}=53 / 6=8,83$ menit

Faktor ketersediaan angkutan,

diasumsikan $\mathrm{f} A=100 \%$.

Waktu sirkulasi dari Terminal Arjosari ke

Terminal Landungsari dan kembali ke

Terminal Arjosari lagi:

$$
\begin{aligned}
\mathrm{CT}_{\mathrm{ADLA}} & =\left(\mathrm{TT}_{\mathrm{ADL}}+\mathrm{TT}_{\mathrm{LDA}}\right)+\left(\mathrm{LT}_{\mathrm{A}}+\mathrm{LT}_{\mathrm{L}}\right) \\
& =(40+40)+(7,25+8,83) \\
& =96,08 \text { menit. }
\end{aligned}
$$

Waktu antara:

$$
\begin{aligned}
H & =(60 \times C \times L f) / P \\
& =(60 \times 32 \times 0,9) / 320 \\
& =5,4 \text { menit }
\end{aligned}
$$

Jumlah armada per-waktu siklus :

$$
\begin{aligned}
\mathrm{K} & =\mathrm{CT}_{\text {ADLA }} /(\mathrm{H} \times \mathrm{fA}) \\
& =96,08 /(5,4 \times 1)
\end{aligned}
$$$$
=17,793 \text { menit, diambil } 18 \text { menit. }
$$

Jumlah kendaraan yang lewat/jam

sibuk (60 menit) :

$$
\begin{aligned}
\mathrm{F}_{\mathrm{KJ}} & =(\mathrm{W} / \mathrm{H})=60 / 5.4 \\
& =11,111 \text { ditetapkan } 12 \text { trip kend. }
\end{aligned}
$$

Waktu tunggu penumpang

Model dengan kapasitas 25 penump.:

$\mathrm{W}_{\mathrm{tp}}=0,5 \mathrm{H}=0,5 \times 4,219=2,11$ menit

Model dengan kapasitas 28 penump.:

$\mathrm{W}_{\mathrm{tp}}=0,5 \mathrm{H}=0,5 \times 4,725=2,363$ menit

Model dengan kapasitas 32 penump.:

$\mathrm{W}_{\mathrm{tp}}=0,5 \mathrm{H}=0,5 \times 5,4=2,7$ menit

Waktu tunggu penumpang dapat dipergunakan untuk penjadwalan keberangkatan kendaraan pada terminal dengan menggunakan masing-masing model angkutan umum.

\section{SIMPULAN DAN SARAN Simpulan}

Kesimpulan yang dihasilkan adalah :

1. Nilai load factor $(127,273 \%>100 \%)$ dan nilai standar kenyamanan yang belum memenuhi kondisi yang ideal $(0,251<0,3-$ $0,55 \mathrm{~m}^{2}$ ). Hal ini mengindikasikan angkutan umum trayek ADL cukup dibutuhkan oleh masyarakat, akan tetapi kualitas atau mutu pelayanan terhadap fungsi kenyamanan belum memenuhi persyaratan, terutama pada saat peak hour. Kecepatan berada dibawah standar yang seharusnya, hal ini disebabkan oleh hambatan dalam perjalanan baik berupa hambatan oleh elemen lalu lintas misalnya lampu lalu lintas, kegiatan land use di sekitar jalan yang dilewati atau perilaku sopir yang memperlambat kendaraan untuk menaikkan atau menurunkan penumpang. Headway yang diperoleh dibawah nilai ideal yaitu 1,179 menit. Dengan headway yang cepat menunjukkan jumlah armada yang 
beroperasi terlalu banyak sehingga perlu dilakukan pengurangan jumlah armada pada trayek ADL untuk dialokasikan pada trayek lain yang membutuhkan atau dilakukan perencanaan angkutan massal di Kotamadya Malang sehingga didapatkan angkutan umum yang efektif dan efisien.

2. Dari hasil perencanaan model angkutan umum massal diperoleh:
a. Model kapasitas 25 penumpang penumpang sebesar 2,110 menit, membutuhkan armada sejumlah 15 trip kendaraan dengan waktu tunggu
b. Model kapasitas 28 penumpang membutuhkan armada sejumlah 13 trip kendaraan dengan waktu tunggu penumpang sebesar 2,363 menit,
c. Model kapasitas 32 penumpang membutuhkan armada sejumlah 12 trip kendaraan dengan waktu tunggu penumpang sebesar 2,700 menit.

\section{Saran}

Adapun saran yang dapat diberikan dari studi ini adalah:

1. Perlu adanya sistem angkutan dengan penjadwalan tetap, khususnya waktu tiba dan waktu berangkat, tanpa dipengaruhi oleh jumlah penumpang, tetapi memperhatikan kapasitas muat kendaraan.

2. Perlu adanya ketegasan dari pihak terkait untuk melaksanakan perundangundangan, khususnya mengenai hak dan kewajiban pemilik, sopir dan penumpang sehingga tujuan pelayanan angkutan umum yang optimal dapat tercapai.

3. Perlu adanya cara untuk meningkatkan kinerja dari pemilik dan pengemudi, khususnya dalam hal disiplin berkendaraan dengan lebih mengutamakan pelayanan pada masyarakat ditinjau dari kecepatan, waktu perjalanan, kenyamanan dan keamanan, sehingga pelayanan angkutan umum lebih berkualitas.

4. Perlu adanya peranan pengguna angkutan umum atau penumpang untuk tidak melakukan hal-hal yang dapat mengurangi kualitas pelayanan angkutan umum, dengan cara menunggu angkutan di halte atau tempat pemberhentian yang disediakan sehingga tidak mengganggu kelancaran pergerakan kendaraan lain di jalan raya.

\section{DAFTAR PUSTAKA}

1996, Pedoman Teknis Penyelenggaraan Angkutan Penumpang Umum di Wilayah Perkotaan dalam Trayek Tetap dan Teratur, Dephub, Jakarta: Dijenhubdat. 1997, Perencanaan Sistem Angkutan Umum (Public Transport System Planning), Modul Pelatihan LPM, Bandung: ITB.

Abubakar, Iskandar, 1996, Menuju Lalu Lintas dan Angkutan Jalan yang Tertib, Dirjenhubdat, Jakarta: PT. Bukit Mayana.

Armstrong, Alan, Urban Transyt Systems-Guidelines for Examining Options, World Bank Technical Papers Number 52.

Burhamtoro, 2001, Penentuan Kapasitas Optimum Angkutan Umum Kota Studi Kasus: Jalur Arjosari - Gadang Kota Malang, Tesis, Surabaya: ITS.

Kadiyali, L.R., 1978, Traffic Engineering and Transport Planning, New Delhi: Khanna Publisher.

Tamin, Ofyar Z., 2000, Perencanaan dan Pemodelan Transportasi, Bandung: ITB.

Vuchic, Vucan R., 1981, Urban Public Transportation System and Technology, New Jersey: Prentice Hall.

Warpani, Suwardjoko, 1990, Merencanakan Sistem Angkutan, Bandung: ITB. 